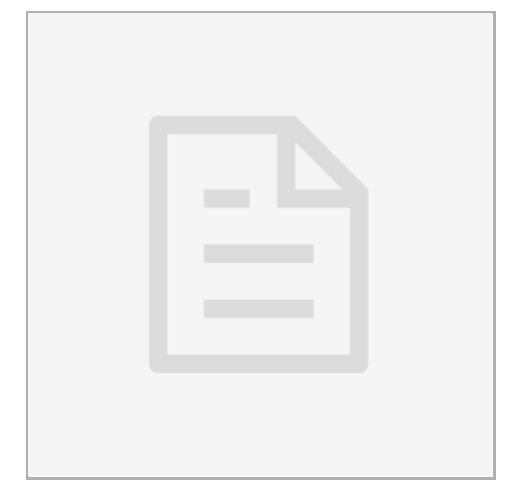

NOV 09, 2020

open ठACcess

DOI:

dx.doi.org/10.17504/protocol s.io.bnrtmd6n

Protocol Citation: Dima TerOvanesyan, Wendy Trieu, Maia Norman, Roey Lazarovits, George Church, David Walt 2020. Tetraspanin (CD9, CD63, CD81) Western Blot for Extracellular Vesicles. protocols.io

https://dx.doi.org/10.17504/p rotocols.io. bnrtmd6n

License: This is an open access protocol distributed under the terms of the Creative Commons Attribution License, which permits unrestricted use, distribution, and reproduction in any medium, provided the original author and source are credited

Protocol status: Working We use this protocol and it's working

Created: Oct 21, 2020

Last Modified: Nov 09, 2020

PROTOCOL integer ID:

43539

\section{(3) Tetraspanin (CD9, CD63, CD81) Western Blot for Extracellular Vesicles}

Dima Ter-Ovanesyan ${ }^{1}$, Wendy Trieu ${ }^{1}$, Maia Norman², Roey Lazarovits ${ }^{1}$, George Church ${ }^{3}$, David Walt ${ }^{2}$

${ }^{1}$ Wyss Institute for Biologically Inspired Engineering;

${ }^{2}$ Wyss Institute for Biologically Inspired Engineering, Brigham and Women's Hospital;

${ }^{3}$ Wyss Institute for Biologically Inspired Engineering, Harvard Medical

School Department of Genetics

Walt Lab

Wendy Trieu

\section{ABSTRACT}

Extracellular vesicles (EVs) are released by all mammalian cells and are thought to be involved in

intercellular communication. Here, we provide a detailed protocol for analyzing the Tetraspanins CD9, CD63 and CD81 by western blotting from EV lysate. These three proteins are widely expressed in different cell types and considered "markers" of EVs. 


\section{MATERIALS}

- Bolt 4x LDS sample buffer (Thermo Fisher Scientific)

- Western Blot mini gel tank (Thermo Fisher Scientific)

- 20x Bolt MES SDS running buffer (Thermo Fisher Scientific)

- $4-12 \%$ Bolt Bis-Tris protein gels (Thermo Fisher Scientific)

- MagicMark XP ladder (Thermo Fisher Scientific)

- SeeBluePlus2 ladder (Thermo Fisher Scientific)

- Power supply

- Dry milk powder (RPI)

- 10\% w/v Tween 20 (Thermo Fisher Scientific)

- Cold room with tilting rocker

- iBlot 2 nitrocellulose mini transfer stacks (Thermo Fisher Scientific)

- iBlot 2 gel transfer device (Thermo Fisher Scientific)

- Blotting roller (Thermo Fisher Scientific)

- Plastic containers such as PerfectWestern (GenHunter) containers

- Primary antibody such as BD (H5C6) for CD63, Millipore Clone MM2/57 (CBL162) for CD9 and Thermo Fisher (M38) for CD81

- PBST: PBS with $0.1 \% \mathrm{vol} / \mathrm{vol}$ Tween 20 . Store at $4{ }^{\circ} \mathrm{C}$.

- Secondary antibody such as HRP conjugated anti-mouse antibody (Bethyl)

- HRP substrate such as WesternBright ECL-spray (Advansta)

\section{Day 1}

1 Add Bolt $4 \mathrm{x}$ LDS sample buffer to samples for a final concentration of $1 \mathrm{x}$ LDS or resuspend in $1 \mathrm{x}$ LDS directly if the samples are pellets.

2 Vortex, spin down, and denature the samples in heat block at $70^{\circ} \mathrm{C}$ for 10 minutes.

3 Fill the Western Blot mini gel tank with 1x MES running buffer.

4 Unwrap the $4-12 \%$ Bolt Bis-Tris protein gels and rinse them with $\mathrm{diH}_{2} \mathrm{O}$. Do not forget to take off the white tape on the bottom. Place the gels in the gel tank, and lock them, making sure the orientation is correct (wells facing you). 
5 Take the combs out slowly and carefully.

$6 \quad$ Wash the wells by pipetting up and down.

7 Load the samples into the gel carefully and do not forget to add unstained protein ladder MagicMark XP and prestained protein ladder SeeBluePlus2 to track progress of gel and assess transfer onto blot.

8 Plug the gel tank into a power supply and run gel at $150 \mathrm{~V}$ for 1 hour. Check that there are bubbles to ensure gel is running.

9 While the gel is running, make blocking buffer (2.50 g dry milk powder in $50 \mathrm{~mL}$ PBS with $500 \mathrm{uL}$ $10 \% \mathrm{w} / \mathrm{v}$ Tween 20 ). Make (20*number of western blots) $\mathrm{mL}$ of blocking buffer because you will need $10 \mathrm{~mL}$ for blocking/primary antibody incubation overnight and $10 \mathrm{~mL}$ for secondary antibody incubation tomorrow. Rock at $4{ }^{\circ} \mathrm{C}$ for an hour.

10 When the run is finished, unlock the gel and wash it with $\mathrm{diH}_{2} \mathrm{O}$. Crack open the gel, and slice the bottom and the top part with wells off.

11 Prepare the iBlot 2 nitrocellulose mini transfer stack for transferring. Take off the foil on top, and set aside the top stack, which contains a copper electrode and transfer gel layer and is separated from the bottom stack by a white plastic separator. Place the bottom stack (containing a copper electrode, transfer gel layer and a nitrocellulose transfer membrane) including the plastic tray into the iBlot 2 gel transfer device. Align the electrical contacts on the tray with the corresponding electrical contacts on the transfer device. Transfer the gel to the nitrocellulose transfer membrane of the bottom stack. 


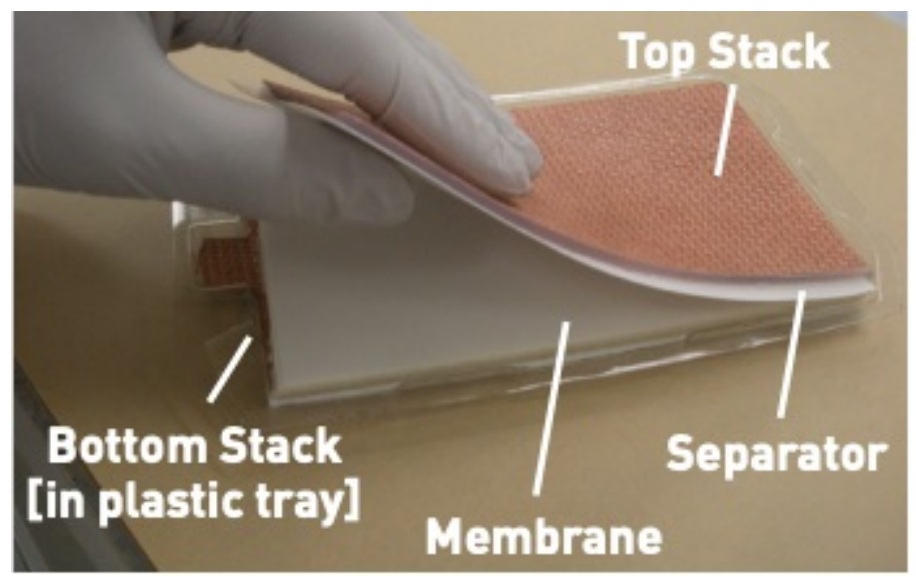

Image from Thermo Fisher Scientific

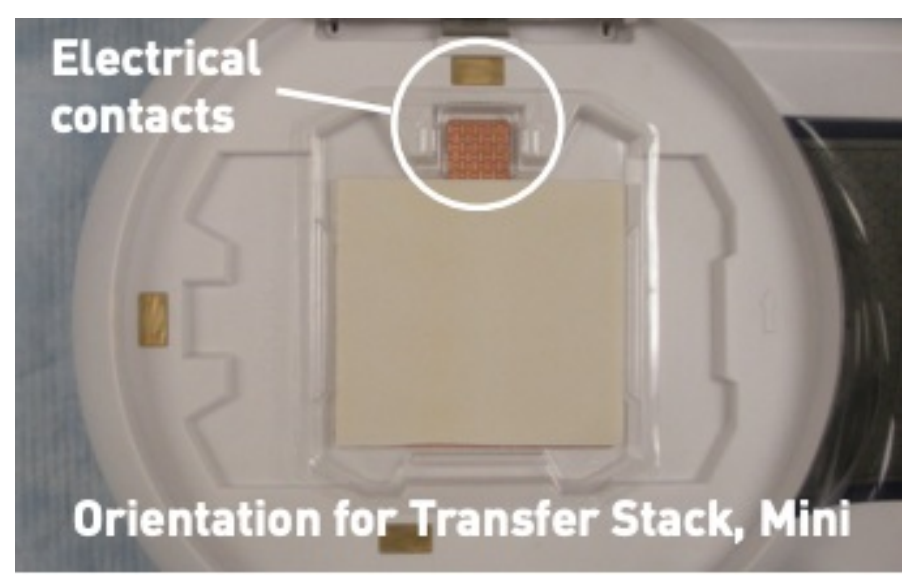

Image from Thermo Fisher Scientific

12 Use a roller on the gel to remove air bubbles. Soak a piece of filter paper in $\mathrm{diH}_{2} \mathrm{O}$ and place it on top, and then add the top stack which was set aside, without the white plastic separator. Lastly place the absorbent pad on top, making sure the electrical contacts are aligned with the corresponding electrical contacts on the transfer device. After every layer added, use the roller to remove air bubbles. Close the lid carefully and use the appropriate transfer protocol (3 minutes for tetraspanins). 


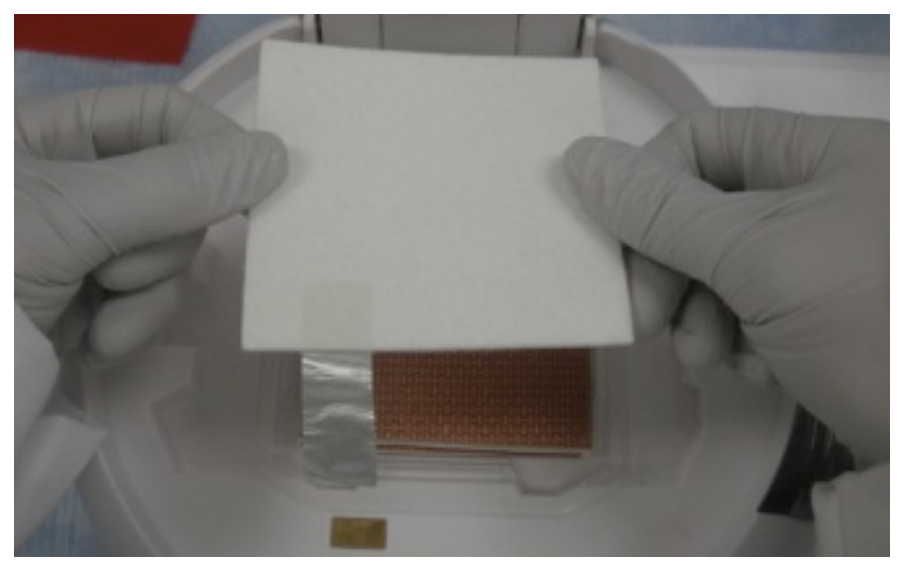

Image from Thermo Fisher Scientific

13 After the transfer is complete, remove all the layers above the transfer membrane (the absorbent pad, top stack, filter paper and the gel) and cut out and place the transfer membrane into a PerfectWestern box with $10 \mathrm{~mL}$ blocking buffer. Rock the container at $4{ }^{\circ} \mathrm{C}$ for 30 minutes to block the membrane.

14 After blocking, pour the blocking buffer from the PerfectWestern boxes into tubes and add primary antibody (1:1000 BD (H5C6) for CD63, 1:1000 Millipore Clone MM2/57 (CBL162) for CD9 and 1:666 Thermo Fisher (M38) for CD81). Add the blocking buffer with the appropriate primary antibody back to each membrane, and rock membranes at $4{ }^{\circ} \mathrm{C}$ overnight.

\section{Day 2}

15 After the overnight primary antibody incubation, wash the membranes 3 times for 10 minutes each with PBST. For the first wash do a double swish. (Add PBST twice to remove the blocking buffer).

16 After washing, add 1:2000 anti-mouse HRP conjugated secondary antibody in blocking buffer to the membranes.

17 Rock at $4^{\circ} \mathrm{C}$ for $2-4$ hours. 
18 After the secondary antibody incubation, wash the membranes 3 times for 10 minutes each with PBST. For the first wash do a double swish like before.

19 After washing, pour out most of the PBST from the PerfectWestern containers. Leave just the minimum amount of liquid needed to prevent the membranes from drying out completely.

20 When you are ready to image, pour out all of the PBST, and then spray (away from the membrane) with enough HRP substrate to cover the membrane sufficiently.

$21 \quad$ Image after 2 minutes. 